\title{
Registration of cancer in girls remains lower than expected in countries with low/middle incomes and low female education rates
}

\author{
SS Bhopal ${ }^{1,2}$, KD Mann ${ }^{2}$ and MS Pearce ${ }^{*, 2}$ \\ 'Newcastle upon Tyne Hospitals NHS Foundation Trust, Royal Victoria Infirmary, Newcastle upon Tyne NEI 4LP, UK; ${ }^{2}$ Institute of Health and Society, \\ Newcastle University, Sir James Spence Institute, Royal Victoria Infirmary, Newcastle upon Tyne NEI 4LP, UK
}

BACKGROUND: A decade ago it was reported that childhood cancer incidence was higher in boys than girls in many countries, particularly those with low gross domestic product (GDP) and high infant mortality rate. Research suggests that socio-economic and cultural factors are likely to be responsible. This study aimed to investigate the association between cancer registration rate sex ratios and economic, social and healthcare-related factors using recent data (1998-2002).

METHODS: For 62 countries, childhood (0-15 years) cancer registration rate sex ratios were calculated from Cancer Incidence in Five Continents Vol IX, and economic, social and healthcare indicator data were collated.

RESULTS: Increased age standardised cancer registration rate sex ratio ( $M: F)$ was significantly associated with decreasing life expectancy $(P=0.05)$, physician density $(P=0.05)$, per capita health expenditure $(P=0.05)$, GDP $(P=0.0 \mathrm{I})$, education sex ratios (primary school enrolment sex ratio $(P<0.0 \mathrm{I})$; secondary school enrolment sex ratio $(P<0.0 \mathrm{I})$; adult literacy sex ratio $(P<0.0 \mathrm{I}))$ and increasing proportion living on less than $\ln \$ \$$ per day $(P=0.03)$.

CONCLUSION: The previously described cancer registration sex disparity remains, particularly, in countries with poor health system indicators and low female education rates. We suggest that girls with cancer continue to go undiagnosed and that incidence data, particularly in low- and middle-income countries, should continue to be interpreted with caution.

British Journal of Cancer (2012) 107, 183-188. doi:10.1038/bjc.2012.191 www.bjcancer.com

Published online 10 May 2012

(C) 2012 Cancer Research UK

Keywords: childhood; health inequalities; low-income countries; middle-income countries; epidemiology

With $86 \%$ of the world's children living in low- and middle-income countries (LIC, MIC), worldwide inequities in child health and access to healthcare are well documented. In 2009, one in eight children in Sub-Saharan Africa did not reach their fifth birthday, compared to fewer than one in 150 in North America (United Nations, 2010). Within this worldwide inequality, there are significant differences within countries, for example, between rural and urban dwellers, and between children of rich and poor families. However, another key factor is a child's sex - a girl in India being $40 \%$ more likely to die between the ages of one and five years old than a boy (Claeson et al, 2000). Explanations for sex-based health differences come from biological, socio-cultural and environmental reasons (Victora et al, 2003). In Punjab (India) and Matlab (Bangladesh), boys are breastfed for longer and given more food after weaning (Elliot and Sorsby, 1979). It has been said that girls receive less and poorer quality healthcare, with studies reporting less money spent on healthcare for girls during the early years of life (Gupta, 1987).

Sex variation in childhood cancer incidence has been noted for some time. These differences are seen most clearly in the haematological malignancies in Europe (Parkes et al, 1994;

*Correspondence: Dr MS Pearce; E-mail: mark.pearce@ncl.ac.uk Received 15 December 2011; revised 12 April 2012; accepted 13 April 2012; published online 10 May 2012
Cartwright et al, 2002), Asia (Nandakumar et al, 1996; Siddiqui et al, 2006) and Africa (Welbeck and Hesse, 1998; Haroun et al, 2006), where Hodgkin's lymphoma, in particular, has been found to be more prevalent in boys, with a considerably greater $\mathrm{M}: \mathrm{F}$ ratio in developing countries (Dinand and Arya, 2006). Calls have been made to analyse girls and boys rates separately (Birch and Blair, 1992; Pramanik et al, 1997) in order to best understand disease patterns, trends and aetiology (Welbeck and Hesse, 1998; Khan et al, 1997; Magnanti et al, 2008).

Global compilations of population-based cancer registries provide an opportunity to explore sex differences in cancer incidence comprehensively. Pearce and Parker (2001) used an International Agency for Research on Cancer (IARC) report (Parkin et al, 1998) to explore 1980's data, finding high registration sex ratios to be associated with decreasing gross domestic product (GDP) and increasing infant mortality rate (IMR) (Pearce and Parker, 2001). This suggested that cancer registration rates in girls were not as high as would be expected in a number of developing countries.

This study used more recent (1998-2002) IARC data (published in Cancer Incidence in Five Continents, Volume IX (CI5 IX; Curado et al, 2007)) and a wider range of national level health, social and economic data to investigate further the associations between cancer registration sex ratios and economic, social and healthcare-related factors - and in particular to examine whether the previously described findings persist. 


\section{MATERIALS AND METHODS}

Cancer Incidence in Five Continents reports data from 1998 to 2002 from 225 cancer registries (5 from Africa; 11 South and Central America; 54 North America; 44 Asia; 100 Europe; and 11 Oceania) detailing cancer cases and incidence rates according to sex, age group and cancer site coded by ICD-10 classification. A total of 182 registries presented independent data. For five countries, where both regional and combined-regional data were presented, only the combined data were used in this analysis. Cases and population data for registries based within the same country were combined, creating a total of 62 data points ( 5 from Africa, 7 South and Central America, 12 North America, 16 Asia, 29 Europe 29 and 3 Oceania 3 ).

Cancer case numbers and age-standardised incidence rates for all cancers and lymphomas were retrieved from CI5 IX. Agestandardised incidence rates were calculated using the method outlined in CI5 IX Chapter 7 (Boniol and Heanue, 2007), taking into account different person-years at risk for countries whose combined registries spanned different time periods.

Sex-specific childhood (under 15 years) population data were retrieved from age-specific tables published in CI5 IX. Cancerreporting regulation data (whether cancer is reportable by legislation, by administrative order without specific law; not reportable or mixed) were collected from within CI5 IX methodological tables.

National level economic (per capita GDP; proportion living on less than Int $\$ 1$ per day), social (primary and secondary school enrolment sex ratios - defined as the ratio of the number of female students enrolled in such schools (both public and private) - to the number of male students), adult literacy ratio (females: males) and healthcare (average life expectancy; physician density per 10000 population; per capita healthcare expenditure and the infant (i.e. 0-1 year) mortality rate per 1000 live births) data were compiled using the UNData web-portal (United Nations Statistics Division, online) for 1998-2002 from primary sources, including the United Nations Statistics Division, the United Nations Children's Fund, the World Health Organisation and the UNESCO Institute for Statistics.

\section{Statistical analysis}

Cancer case sex ratios (male: female) and age-standardised cancer rate sex ratios (accounting for underlying $\mathrm{M}: \mathrm{F}$ population differences) were calculated for all cancers; Hodgkin's lymphoma (HL), non-Hodgkin's lymphoma (NHL) and 'non-lymphoma cancer' designated as those excluding HL and NHL. Explanatory variables, detailed above, were defined on continuous scales except for 'cancer reporting regulation', which was treated as categorical. Relationships between the dependent variables (the cancer rate sex ratios) and explanatory variables were estimated by linear regression, with fractional polynomials used where evidence existed for non-linear associations (Royston et al, 1999).

F-tests were used to assess associations between the dependent variable and continuous explanatory variables. The Kruskal-Wallis test was used to assess associations between the dependent variables and the categorical variable, cancer-reporting regulation. The statistical software package Stata, version 10 (StataCorp., College Station, TX, USA) was used for all analyses.

\section{RESULTS}

Significant correlations were seen between most of the explanatory variables included in this study (Table 1 , where correlations with $P<0.05$ are denoted by asterisk $\left.\left({ }^{*}\right)\right)$. There was a large range of age-standardised cancer rate sex ratios (from 0.66 in Thailand to 1.84 in Bahrain; Table 2). Excluding lymphomas, the range was similarly wide (from 0.61 in Thailand to 1.82 Bahrain).

The majority of countries had an age-standardised cancer rate sex ratio of less than 1.4 (Table 2), with nine countries ratio being greater than this (China 1.42; Singapore 1.46; Egypt 1.48; Uganda 1.49; India 1.57; Pakistan 1.58; Zimbabwe 1.60; Chile 1.71; Bahrain 1.84). Excluding lymphomas, again, most countries had an agestandardised cancer rate sex ratio less than 1.4 with six countries having a rate ratio greater than this (India 1.45; Zimbabwe 1.47; Pakistan 1.48; Uganda 1.54; Chile 1.56; Bahrain 1.82). A number of countries had age-standardised cancer rate ratios of less than one (Argentina 0.97; Poland 0.97; Oman 0.96; Cyprus 0.91; Lithuania 0.89; Thailand 0.66). All of these had wide confidence intervals, with only the interval for Thailand excluding 1 (Table 2).

Significant associations were found between a number of explanatory variables and the age-standardised cancer rate sex ratios (Table 3). Increasing cancer rate sex ratio was significantly associated with increasing proportion of those living on less than Int $\$ 1$ per day $(P<0.02)$, decreasing GDP $(P<0.01)$, healthcare variables including decreasing life expectancy $(P=0.03)$, decreasing physician density $(P=0.05)$, decreasing per capita health expenditure $(P=0.01)$ and increasing IMR $(P<0.01)$. Increasing cancer rate sex ratios were also significantly associated with sociocultural variables including both education sex ratios (primary $P<0.01$, secondary $P<0.01$ ) and decreasing $\mathrm{F}: \mathrm{M}$ adult literacy ratio $(P<0.01)$. There was no significant association between reporting regulations and cancer rate sex ratio $(P=0.266)$.

All of these associations persisted when lymphomas were excluded. Adjustment to account for differences in registry size had little effect on the reported associations. Multiple regression models yielded uninterpretable results due to multi-colinearity of the independent variables.

Table I Correlation ( $r$ ) between the independent variables included in this study

\begin{tabular}{|c|c|c|c|c|c|c|c|c|c|}
\hline & $\begin{array}{c}\text { GDP } \\
\text { per capita } \\
\text { (PPP } \\
\text { Int \$) }\end{array}$ & $\begin{array}{c}\text { IMR } \\
\text { (0-I year) } \\
\text { per I000 } \\
\text { live } \\
\text { births }\end{array}$ & $\begin{array}{c}<\text { I } \\
\text { PPP } \\
\text { Int \$ } \\
\text { per } \\
\text { day (\%) }\end{array}$ & $\begin{array}{c}\text { Life } \\
\text { expectancy } \\
\text { at birth } \\
\text { (years) }\end{array}$ & $\begin{array}{l}\text { Per capital } \\
\text { total } \\
\text { expenditure } \\
\text { on health } \\
\text { (PPP Int \$) }\end{array}$ & $\begin{array}{c}\text { Physician } \\
\text { density } \\
\text { (per } 10000 \\
\text { population) }\end{array}$ & $\begin{array}{l}\text { Primary } \\
\text { school } \\
\text { enrolment } \\
\text { ratio } \\
\text { F: M }\end{array}$ & $\begin{array}{l}\text { Secondary } \\
\text { school } \\
\text { enrolment } \\
\text { ratio } \\
F: M\end{array}$ & $\begin{array}{c}\text { Adult } \\
\text { literacy } \\
\text { ratio }\end{array}$ \\
\hline GDP per capita (PPP Int \$) & 1.00 & & & & & & & & \\
\hline IMR (0-I year) per 1000 live births & $-0.53^{*}$ & 1.00 & & & & & & & \\
\hline$<1$ Int $\$$ per day & $-0.43^{*}$ & $0.87^{*}$ & 1.00 & & & & & & \\
\hline Life expectancy at birth (years) & $0.62 *$ & $-0.88 *$ & $-0.77^{*}$ & 1.00 & & & & & \\
\hline $\begin{array}{l}\text { Per capital total expenditure on } \\
\text { health (PPP int \$) }\end{array}$ & $0.91 *$ & $-0.55^{*}$ & $-0.45^{*}$ & $0.64 *$ & 1.00 & & & & \\
\hline $\begin{array}{l}\text { Physician density (per } 10000 \\
\text { population) }\end{array}$ & $0.44 *$ & $-0.67^{*}$ & $-0.59 *$ & $0.63 *$ & $0.53 *$ & 1.00 & & & \\
\hline Primary school enrolment ratio F:M & $0.36 *$ & $-0.74 *$ & $-0.55^{*}$ & $0.55^{*}$ & $0.37 *$ & $0.40 *$ & 1.00 & & \\
\hline Secondary enrolment ratio & 0.22 & $-0.77 *$ & $-0.65^{*}$ & $0.63^{*}$ & 0.24 & $0.42^{*}$ & $0.77 *$ & 1.00 & \\
\hline Adult literacy ratio & $0.38^{*}$ & $-0.8 I^{*}$ & $-0.63^{*}$ & $0.59 *$ & $0.44^{*}$ & $0.52 *$ & $0.87 *$ & $0.79 *$ & 1.00 \\
\hline
\end{tabular}

Abbreviations: GDP = gross domestic product; IMR = infant mortality rate; PPP Int $\$ P=$ purchasing power parity international dollars. 
Table 2 Global Childhood cancer, economic, healthcare and social data for the 62 countries included in this study

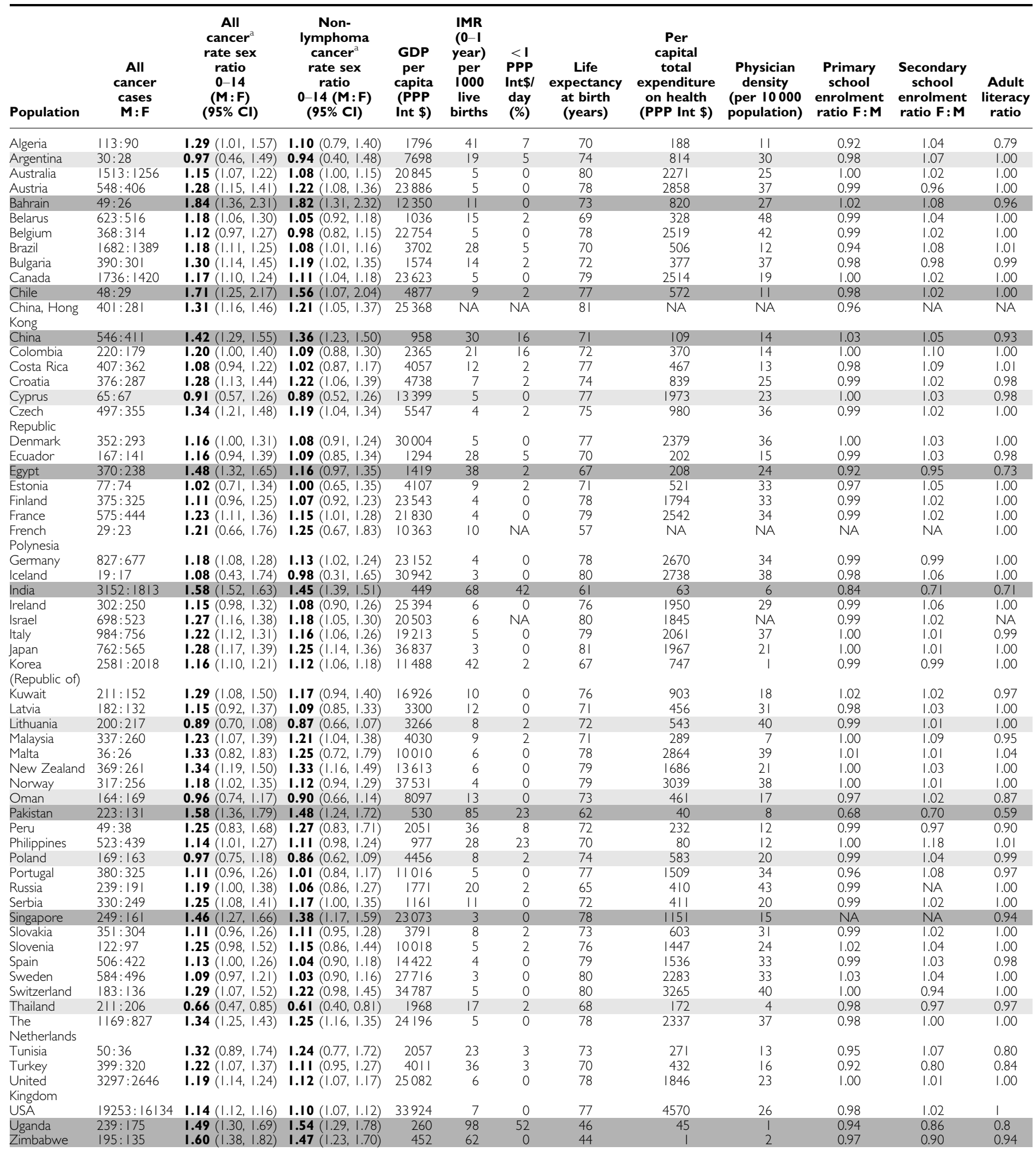

Abbreviations: GDP = gross domestic product; IMR = infant mortality rate; NA = not available; PPP Int $\$=$ purchasing power parity international dollars. Dark highlight = top nine cancer rate sex ratios ( $>$ I.4); Light highlight $=$ cancer rate sex ratio $<1 .{ }^{a}$ Age standardised.

From calculated $R^{2}$ values in the univariate models, the most important predictor of all cancer rate sex ratio was adult literacy sex ratio (accounting for $17 \%$ of the variation) and IMR (accounting for 18\%) (Table 3).

\section{DISCUSSION}

We found that rates of cancer registrations in girls remain lower than expected in LIC and MIC, even when lymphomas were 
Table 3 Results of unadjusted regression models between age standardised all cancer rate sex ratio and independent variables

\begin{tabular}{|c|c|c|c|c|}
\hline Variable & Co-efficient & $95 \% \mathrm{Cl}$ & $\mathbf{P}$ & $\mathbf{R}^{2}$ \\
\hline GDP per capita (PPP Int \$) & -0.01 & $0.00,0.02$ & 0.002 & 0.15 \\
\hline IMR (0-I year) per 1000 live births & 0.01 & $0.00,0.01$ & 0.001 & 0.18 \\
\hline < I PPP Int\$/day (\%) & 0.01 & $0.00,0.01$ & 0.015 & 0.10 \\
\hline Life expectancy at birth (years) & -0.01 & $-0.01,0.00$ & 0.027 & 0.08 \\
\hline Per capital total expenditure on health (PPP $\operatorname{lnt} \$)^{\mathrm{a}}$ & -0.04 & $-0.08,-0.01$ & 0.013 & 0.10 \\
\hline Physician density (per 10000 population) ${ }^{b}$ & --0.11 & $-0.22,0.01$ & 0.050 & 0.06 \\
\hline Primary school enrolment ratio F:M & 0.88 & $0.16,1.60$ & 0.017 & 0.09 \\
\hline Secondary school enrolment ratio F:M & 0.75 & $0.27,1.24$ & 0.003 & 0.15 \\
\hline Adult literacy ratio $\mathrm{F}: \mathrm{M}$ & -0.95 & $-1.50,-0.40$ & 0.001 & 0.17 \\
\hline
\end{tabular}

Abbreviations: GDP = gross domestic product; IMR = infant mortality rate; PPP Int $\$=$ purchasing power parity international dollars. ${ }^{a}$ Log transformation. ${ }^{b}$ Square root transformation.

excluded from analysis. The strongest association was with adult literacy sex ratio, suggesting a strong persisting influence of social indicators, but also with economic, healthcare and other social indicators.

Our study has several fundamental strengths. We used high quality validated data from CI5 IX, with in-built quality controls including a check on abrupt changes in cancer cases and rates year by year - both measures of completeness (Ferley, 2007). Using exclusively population-based registries allowed for the most accurate record held to be explored in these data. Both case and age standardised rate sex ratios were calculated. The case sex ratio was generally larger than the rate ratio for a country. However, associations

with variables were similar. The calculation of rate sex ratios is an improvement compared with previous methods of using case ratios, which assumed a $\mathrm{M}: \mathrm{F}$ population ratio of close to one. Using CI5 IX data allowed for analysis by cancer type and age. Crucially it allowed the calculation of a 'non-lymphoma cancer' rate ratio, showing that the known higher male incidence of $\mathrm{HL}$ and NHL is not the sole reason for our finding of a raised incidence of reported cancer in boys.

Accuracy of rate ratios calculation relies on accuracy of population data. These data are usually outwith the control of cancer registry officials, and particularly in LIC and MIC may be subject to rapid shifts owing to, for example, migration, refugees or rapid changes in birth and death rates (Howard et al, 2008).

There is a some variation in registration methods between registries as noted in Chapter 5 in CI5 IX (Shin et al, 2007). Some countries require reporting of cancer through legislation, while in others cancer is not a reportable disease. Case-finding methods vary considerably, with some registries including only public hospitals and not covering private hospital and clinics. Some use autopsy reports, death certificates and screening programmes while others do not. It has been reported that the experienced cancer registries record much higher incidence of childhood cancer (Swaminathan et al, 2008), suggesting that case-finding can be improved. However, we found little evidence that reporting legislation had an effect on our findings. Additionally, it is clear that CI5 IX editors made considerable efforts to enhance comparability, stating that their aim 'is to present comparable incidence rates of cancer from different populations worldwide'. This is done through attention to definition of incidence, multiple primaries, incidental and autopsy diagnosis, and coding practice. Completeness was checked using a variety of methods wherever possible including comparison with historic data, proportion of cases microscopically diagnosed, proportion of unknown basis of diagnosis, mortality:incidence (M:I) ratio and death certificate method. Importantly, the editors use this information to decide which of the submitted data are of high enough quality to include in the final report.

The use of national level economic, social and healthcare data gave an indication as to the likely local reality in an area covered by a regional registry. However, these data cannot account for within-country variations, rural/urban differences being of particular note, and in some countries, the registries have an urban population focus. Ideally, these economic, social and healthcare data would be collected from the exact cancer registry population, but this is often not possible. Additionally, these data have in-built errors, often due to poor reporting and data collection methods. For example, vital registration data on mortality rates is notoriously poor (Mathers et al, 2005), particularly in LIC and MIC.

A number of countries that were considered in Pearce and Parker's (2001) previous paper were not included within our data set as they were not included in CI5 IX. A number of cancer registries were not accepted by IARC for publication in CI5 IX due to quality control reasons. Similarly, presented data are available in the literature and online (Banda et al, 2001); however, those have not been subject to CI5 IX quality controls, so were excluded from our analysis.

We cannot comment on whether the true incidence of cancer is smaller overall in girls compared with boys, rather we found that girls are being registered less than boys. Girls with cancer may also be under-diagnosed compared with boys. There remains a question over why girls are missed. Howard et al (2008) described the 'links in the chain of childhood cancer diagnosis and registration', pointing to the multiple steps needed for a child with cancer to be registered. First, an unwell child must be recognised as such by family or community, they then must access primary care, be diagnosed, referred and reach a tertiary referral centre, have a thorough histological diagnosis of cancer in a laboratory and finally be registered in a database. There are multiple risks and barriers at and between each of these steps, including poor parental awareness, lack of transportation, poorly qualified healthcare staff, lack of laboratory and diagnostic equipment, lack of money to pay for treatment and so on. The population-based registries that contributed to CI5 IX aim to overcome this problem through a variety of case-finding methods including hospital in-patient records, radiotherapy departments, public and private hospitals, their in- and out-patient facilities, pathology laboratories, autopsies, haematology laboratories, death certificates, and screening programmes.

Our findings fit with previous data describing that sick girls tend not to be taken for healthcare as much or as early as boys (Gupta, 1987; Hossain and Glass, 1988; Sauerborn et al, 1996; Kurz and Johnson-Welch, 1997; Swaminathan et al, 2008), suggesting that this may be a break in the chain. Of particular interest is that while indicators, including GDP and IMR, have improved considerably since Pearce and Parker's previous paper, the previously described association remains. This is somewhat expected finding, in that we would not expect an improvement in GDP (a weak indicator of individual and community wealth) to lead directly to improvement in cancer services, particularly over just one decade. In addition, improved overall child survival figures are likely to have emerged from improvements in other conditions.

The main current explanation suggests that that there is a sex-biased inequity related to inferior status of the girl child in 
developing countries (Chen et al, 1981). Indeed, this explanation is often alluded to by authors studying childhood cancer incidence (Yaris et al, 2004; Agboola et al, 2009) with still little empirical evidence available. Our finding that those countries with poorer markers of female education are more likely to have missing girls would appear to support this hypothesis. It may be that when resources are limited, culture and economics favour boys.

Further research is required to explore our hypotheses, particularly whether culture and economics favour boys, and at which point in the 'chain' of cancer registration girls are being missed. While there remains a debate over whether child cancer care in general is a useful healthcare priority (Markman, 2005), other research is tied to a general sex equity agenda, for example, by finding ways of encouraging families to seek care for their girls and improving healthcare service design to increase accessibility to all.

Most children live in LIC and MIC; however, the majority of cancer registries are based in high-income countries. Recent initiatives have focussed on twinning of experienced paediatric oncology units to cross this divide (Masera et al, 1993; Masera et al, 1998; Cole, 2004), both in clinical management of children and in supporting data collection and cancer registry formation and continuation. These data are needed to add further evidence to our findings and to explore further the reasons behind them.

\section{CONCLUSION}

Our findings suggest that the previously described cancer registration sex disparity remains, particularly in countries with poor health system indicators and low female education rates. We suggest that girls with cancer continue to go undiagnosed and that incidence data - particularly in LIC and MIC - should continue to be interpreted with caution.

\section{Conflict of Interest}

The authors declare no conflict of interest.

\section{REFERENCES}

Agboola AOJ, Adekanmbi FA, Musa AA, Sotimehin AS, Deji-Agboola AM, Shonubi AMO, Oyebadejo TY, Banjo AAF (2009) Pattern of childhood malignant tumours in a teaching hospital in south-western Nigeria. Med J Aust 190: 12-14

Banda LT, Parkin DM, Dzamalala CP, Liomba NG (2001) Cancer incidence in Blantyre, Malawi 1994-1998. Trop Med Int Health 6: 296-304

Birch JM, Blair V (1992) The epidemiology of infant cancers. Br J Cancer Supplement 18: S2-S4

Boniol M, Heanue M (2007) Age-Standardisation and Denominators. In, Cancer Incidence in Five Continents. Curado MP, Edwards B, Shin HR, Ferlay J, Heanue M and Boyle P (eds), Vol. IX, Chapter 7, International Agency for Research on Cancer Scientific Publications No 160: Lyon

Cartwright RA, Gurney KA, Moorman AV (2002) Sex ratios and the risks of haematological malignancies. Br J Haematol 118: 1071-1077

Chen LC, Huq E, D'Souza S (1981) Sex bias in the family allocation of food and health care in rural Bangladesh. Popul Dev Rev 7: 55-70

Claeson M, Bos ER, Mawji T, Pathmanathan I (2000) Reducing child mortality in India in the new millennium. Bull World Health Organ 78: 1192-1199

Cole C (2004) Registering childhood cancers. Lancet 364: 2074-2076

Curado MP, Edwards B, Shin HR, Storm H, Ferlay J, Heanue M, Boyle P (2007) Cancer Incidence in Five Continents. International Agency for Research on Cancer: Lyon

Dinand V, Arya LS (2006) The epidemiology of childhood Hodgkin's disease: is it different in developing countries? Indian Pediatr 43: 141-147

Elliot V, Sorsby V (1979) An Investigation into Evaluations of Projects Designed to Benefit Women. Office of Evaluation, Bureau of Program and Policy Coordination USAID

Ferley J (2007) Processing of Data. In, Cancer Incidence in Five Continents. Curado MP, Edwards B, Shin HR, Ferlay J, Heanue M and Boyle P (eds), Vol. IX, Chapter 6, International Agency for Research on Cancer Scientific Publications No 160: Lyon

Gupta MD (1987) Selective discrimination against female children in rural Punjab, India. Population Devel Rev 13: 77-100

Haroun HM, Mahfouz MS, Elhaj AM (2006) Patterns of childhood cancer in children admitted to the institute of nuclear medicine, molecular biology and oncology (INMO), Wad Medani, Gezira state. J Fam Community Med 13(2): 71-74

Hossain MM, Glass RI (1988) Parental son preference in seeking medical care for children less than five years of age in a rural community in Bangladesh. Am J Public Health 78: 1349-1350

Howard SC, Metzger ML, Wilimas JA, Quintana Y, Pui C, Robison LL, Ribeiro RC (2008) Childhood cancer epidemiology in low-income countries. Cancer 112: 461-472

Khan SM, Gillani J, Nasreen S, Zai S (1997) Pediatric tumors in north west Pakistan and Afghan refugees. Pediatr Hematol Oncol 14: 267-272

Kurz KM, Johnson-Welch C (1997) Gender differences among children 0-5 years: an opportunity for child survival interventions. A review paper prepared for the BASICS project USAID/BASICS II, Arlington, VA.

Magnanti BL, Dorak MT, Parker L, Craft AW, James PW, McNally RJQ (2008) Sex-specific incidence and temporal trends in solid tumours in young people from Northern England, 1968-2005. BMC cancer 8: 89

Markman M (2005) Care of pediatric cancers in the developing world: Should this be a societal priority? Curr Oncol Rep 7: 81-82

Masera G, Baez F, Biondi A, Cavalli F, Conter V, Flores A, Fontana G, Fossati Bellani F, Lanfranco P, Malta A, Mendez G, Ocampo E (1998) North-South twinning in paediatric haemato-oncology: The La Mascota programme, Nicaragua. Lancet 352: 1923-1926

Masera G, Baez Lacayo F, Malta Corea A, Ocampo Hernandez E, Pacheco Espinoza C, Silva Espinoza F, Conter V, Biondi A, Lietti G, Sessa C (1993) Pediatric oncology in developing countries: a cooperative program in Nicaragua. Ann Oncol 4: 37-40

Mathers CD, Ma Fat D, Inoue M, Rao C, Lopez AD (2005) Counting the dead and what they died from: an assessment of the global status of cause of death data. Bull of WHO 83: 171-177

Nandakumar A, Anantha N, Appaji L, Swamy K, Mukherjee G, Venugopal T, Reddy S, Dhar M (1996) Descriptive Epidemiology of Childhood Cancers in Bangalore, India. Cancer Causes Control 7: 405-410

Parkes SE, Coad NA, Muir KR, Jones TJ, Cameron AH, Mann JR (1994) Hodgkin's disease in children in the West Midlands, 1957-1986: a large population-based study. Pediatr Hematol Oncol 11: 471-486

Parkin DM, Kramarova E, Draper GJ, Masuyer E, Michaelis J, Neglia J, Qureshi S, Stiller CA (eds) (1998) International Incidence of Childhood Cancer vol. 2, IARC Scientific Publications no. 144. International Agency for Research on Cancer: Lyon

Pearce MS, Parker L (2001) Childhood cancer registrations in the developing world: still more boys than girls. Int J Cancer 91: 402-406

Pramanik R, Paral CC, Ghosh A (1997) Pattern of solid malignant tumours in children-a ten-year study. I Indian Med Assoc 95: 107-108

Royston P, Ambler G, Sauerbrei W (1999) The use of fractional polynomials to model continuous risk variables in epidemiology. Int J Epidemiol 28: 964-974

Sauerborn R, Berman P, Nougtara A (1996) Age bias, but no gender bias, in the intra-household resource allocation for health care in rural Burkina Faso. Health Trans Rev 6: 131-145

Shin HR, Curado MP, Ferlay J, Heanue M, Edwards B, Storm H (2007) Comparability and quality of data. In, Cancer Incidence in Five Continents. Curado MP, Edwards B, Shin HR, Ferlay J, Heanue M and Boyle P (eds), Vol. IX, Chapter 5, International Agency for Research on Cancer Scientific Publications No 160: Lyon,

Siddiqui N, Ayub B, Badar F, Zaidi A (2006) Hodgkin's lymphoma in Pakistan: a clinico-epidemiological study of 658 cases at a cancer center in Lahore. Asian Pac J Cancer Prev 7: 651-655

Swaminathan R, Rama R, Shanta V. Childhood cancers in Chennai, India, 1990-2001: incidence and survival (2008) Int J Cancer 122: 2607-2611

United Nations. Levels and Trends in Child Mortality: Report 2010. Estimates Developed by the UN Inter-agency Group for Child mortality 
Estimation. http://www.childinfo.org/files/Child_Mortality_Report_2010. pdf (accessed 7 December 2011)

United Nations Statistics Division. UNData: A World of Information Version v0.14.4 Beta. http://data.un.org (accessed 10 December 2010)

Victora CG, Wagstaff A, Schellenberg JA, Gwatkin D, Claeson M, Habicht JP (2003) Applying an equity lens to child health and mortality: more of the same is not enough. Lancet 362: 233-241

Welbeck JE, Hesse AA (1998) Pattern of childhood malignancy in Korle Bu Teaching Hospital, Ghana. West Afr J Med 17: 81-84

Yaris N, Mandiracioglu A, Büyükpamukcu M (2004) Childhood cancer in developing countries. Pediatr Hematol Oncol 21: 237-253

This work is published under the standard license to publish agreement. After 12 months the work will become freely available and the license terms will switch to a Creative Commons Attribution-NonCommercial-Share Alike 3.0 Unported License. 